\title{
Carotid Intima-Media thickness (C-IMT) in androgenic alopecia patient A.I.El-Taweel ${ }^{1}$, A.M.Hamed ${ }^{1}$, A.M.Noureldin ${ }^{2}$ and Y.A.Mohamed ${ }^{1}$ \\ ${ }^{1}$ Dermatology, Venereology and Andrology, Dept., Faculty of Medicine, Benha Univ., Benha, Egypt \\ ${ }^{2}$ Clinical and Chemical Pathology, Dept., Faculty of Medicine, Benha Univ., Benha, Egypt \\ E-mail: gana.a7mad84@gmail.com
}

\begin{abstract}
Bachground: Androgenic alopecia is a prevalent hair loss that affects $80 \%$ of males and $50 \%$ of women throughout their lives. The objective of this research was to evaluate the thickness of the Carotid Intima-Media (C-IMT) in young androgenic alopecia patients. Methods: The research comprised 30 young women with AGA. Furthermore, 30 people who were seemingly healthy, age and sex matched as a control group. All patients were chosen from the Dermatology and Andrology outpatient clinic, Benha University Hospitals. Every patient was exposed to With history, dermatological exam to assess the severity of AGA, via general clinical examination and excluding other skin conditions, Laboratory Investigations: Serum lipid profile: serum cholestenol, triglycerides (TGs), lipoprotein (HDL) high density and lipoprotein of very low density (VLDL), Carotid intima-media thickness measurement (C-IMT) Results: In patients and lipid profile controls, there was no statistically significant difference. In the sick group, there was a statistically significant rise in CIMT compared to the control group. Conclusion: Increased CIMT susceptibility to atherosclerosis in AGA patients is indicative.
\end{abstract}

Keywords: CMIT, atherosclerosis, androgenic, alopecia.

\section{Introduction}

A frequent type of hair loss affects androgenic alopecia (AGA) in up to 80 percent of men (male hair loss pattern) and 50 percent of women (female hair loss patterns) throughout their lives[1].

It is associated with the hormonal consequences of high dihydrotesterone levels (DHT), which are transformed into enzyme 5-alpha-minctase from testosterone. DHT is responsible for temporary scalp hair regression, terminal bear hair growth, external ore, nose and limb growth, and acne. The sensitivity of scalp hair to androgen hormones causes progressive hair thinning in front / midline / vertex areas for males and the midline and female crown, since androgen concentrations are normally within normal limits [2].

Clinically, in different regions of the scalp there is gradual replacement of terminal hair with fine, practically unpigmented villus hair with hair loss. Diversity of the hair diameter is an essential clinical indication reflecting the feature of this disease. Increased hair removal is often noticed. The hair loss is patterned in females and affects the frontal, central, and temporal areas [1].

Hair loss may have a significant psychological impact, especially in younger women[3].

The purpose of this research was to evaluate the thickness of carotid intima-media (C-IMT) in young androgenic individuals.

\section{Patients and methods}

This study was a comparative cross sectional study which was approved by the Research Ethics Committee of the Faculty of Medicine, Benha University. This study was conducted on 30 young female patients (age 18-30 years) suffering from AGA and 30 age and sex-matched and BMI matched healthy controls, both recruited from Dermatology outpatient clinic, Faculty of Medicine, Benha University Hospital in the period between May 2018 and Dec 2018.

\subsection{Inclusion criteria}

- Patients with any grade of AGA.

- Age from 18 to 30 years old.

- Female patients only.

\subsection{Exclusion criteria}

- Any patient with other dermatological disease.

- Age $>30 y e a r s$ old.

- Any other systemic disease.

Each patient were subjected to Through history taking, through general clinical examination, Dermatological examination to evaluate the severity of AGA and excluded any other skin disease, Laboratory Investigations: Serum lipid profile in the form of: serum cholesterol, triglycerides (TGs), high density lipoprotein (HDL) and very low density lipoprotein (VLDL), Measurement of Carotid Intima-Media thickness (C-IMT)

Measurment of CIMT By ultrasonographic studies on common carotid artery on both sides by using high-rosolution doppler ultrasound (ATL 5000) with a 5-12 MHz linear transducer. A single blinded operator performed all measurents on two stored longitudinal images of each artery the four values were averaged to calculate mean c-IMT.

\subsection{Statistical analysis}

Data were collected, coded, revised and entered to the Statistical Package for Social Science (IBM SPSS) version 20. The data were presented as number and percentages for the qualitative data, mean, standard deviations and ranges for the quantitative data with parametric distribution and median with inter quartile range (IQR) for the quantitative data with non parametric distribution. Chi-square test was used in the comparison between two groups with qualitative data and Fisher exact test was used instead of the Chisquare test when the expected count in any cell found less than 5. Independent t-test was used in the 
comparison between two groups with quantitative data and parametric distribution and Mann-Whitney test was used in the comparison between two groups with quantitative data and non parametric distribution.

\section{Results}

This study was conducted on 30 young female patients (age 18-30 years) suffering from AGA and 30 age, sex-matched and BMI matched healthy controls. There was no statistically significant difference in demographic data regarding studied groups Table (1).

Table (1) Comparison between patients group and control group as regards demographic data.

\begin{tabular}{|c|c|c|c|c|c|c|}
\hline & \multicolumn{2}{|c|}{$\begin{array}{l}\text { Patients } \\
(\text { No.=30) }\end{array}$} & \multicolumn{2}{|c|}{$\begin{array}{l}\text { Controls } \\
(\text { No.=30) }\end{array}$} & \multicolumn{2}{|c|}{ Independent $\mathrm{t}$ test } \\
\hline & Mean & SD & Mean & SD & $\mathbf{T}$ & $p$ value \\
\hline Age(years) & 27.350 & 2.44 & 26.100 & 2.52 & 0.060 & 0.82 \\
\hline BMI(kg/m2) & 24.180 & 1.03 & 23.91 & 1.71 & 1.410 & 0.94 \\
\hline
\end{tabular}

There was no statistically significant difference in Smoking regarding studied groups Table (2).

Table (2) Comparison between patients group and control group as regards smoking.

\begin{tabular}{|c|c|c|c|c|c|c|}
\hline & & \multicolumn{2}{|c|}{$\begin{array}{l}\text { Patients } \\
(\text { No.=30) }\end{array}$} & \multicolumn{2}{|c|}{$\begin{array}{l}\text { Controls } \\
(\text { No.=30) }\end{array}$} & \multirow{2}{*}{$\begin{array}{c}\text { Fisher exact test } \\
\text { p value }\end{array}$} \\
\hline & & $\mathbf{N}$ & $\%$ & $\mathbf{N}$ & $\%$ & \\
\hline Smoking & $\begin{array}{l}\text { Yes } \\
\text { No }\end{array}$ & $\begin{array}{c}3 \\
27\end{array}$ & $\begin{array}{l}10 \\
90\end{array}$ & $\begin{array}{c}1 \\
29\end{array}$ & $\begin{array}{c}3.3 \\
96.7\end{array}$ & 0.61 \\
\hline
\end{tabular}

According to Ludwig scale of severity, 15 (50\%) patients had Grade I AGA, 10(33.3\%) had Grade II and only five patients reported as Grade III. Eleven (36.6\%) patients reported to have positive family history of AGA, mean duration of AGA was 3.01 years Table (3).

Table (3) Clinical data in patients group.

\begin{tabular}{llcc}
\hline & & No & \% \\
\hline \multirow{3}{*}{ Severity } & Grade 1 & 15 & $50 \%$ \\
& Grade 2 & 10 & $33.3 \%$ \\
Family history & Grade 3 & 5 & $16.7 \%$ \\
Duration (years) & No & 19 & $63.4 \%$ \\
& Yes & 11 & $36.6 \%$ \\
\hline
\end{tabular}

There was statistically significant increase in patient group in comparison to control group in right and left CMT Table (4)

Table (4) Comparison between patient group and control group as regards right and left CMT.

\begin{tabular}{llcccccc}
\hline & & \multicolumn{2}{c}{$\begin{array}{c}\text { Patients } \\
(\text { No.=30) }\end{array}$} & \multicolumn{2}{c}{$\begin{array}{c}\text { Controls } \\
\text { (No.=30) }\end{array}$} & \multicolumn{2}{c}{ Independent t test } \\
& & Mean & SD & Mean & SD & T & p value \\
\hline \multirow{2}{*}{ CMT(CM) } & Left & 0.0488 & 0.011 & 0.040 & 0.006 & 3.023 & $<0.001 *$ \\
& Right & 0.049 & 0.09 & 0.040 & 0.005 & 2.81 & $<0.001 *$ \\
\hline
\end{tabular}

$* * \mathrm{P}<0.01$ : Highly significant (HS)

There was no statistically significant difference between patients and controls regarding lipid profile Table( 5).

Table (6) Comparison between patient group and control group as regards lipid profile.

\begin{tabular}{llccccccc}
\hline & & \multicolumn{2}{c}{$\begin{array}{c}\text { Patients } \\
\text { (No.=50) }\end{array}$} & \multicolumn{2}{c}{$\begin{array}{c}\text { Controls } \\
\text { (No.=30) }\end{array}$} & \multicolumn{2}{c}{ Independent t test } \\
& & Mean & SD & Mean & SD & t & p value \\
\hline \multirow{2}{*}{ Lipid profil (mg/dl) } & S. Ch & 182.36 & 51.2 & 192.7 & 42.19 & 2.26 & 0.41 \\
& S. TG & 171.8 & 66.81 & 161.9 & 61.8 & 0.62 & 0.72 & 0.5 \\
& HDL & 83.19 & 20.18 & 79.64 & 18.19 & 0.738 & 0.61 \\
\hline
\end{tabular}

$* \mathrm{P}<0.05:$ Significant $(\mathrm{S})$ 


\section{Discussion}

This research comprised 30 young women who had AGA. Furthermore, 30 people who were seemingly healthy, age and sex matched as a control group. All patients were chosen from Benha University Hospitals, the Dermatology and Andrology outpatient clinic. All subjects received written informed consent. The study was authorised by the Benha Faculty of Medicine's Local Ethics Committee for research involving human participants.

Our findings revealed that among patients and lipid profile controls there was no statistically significant difference.

Our findings did not accord with Kim et al. [4] Total cholesterol, TG, and LDL cholesterol levels were found to be higher and HDL cholesterol in AGA patients to be lower than controls. The mechanism underlying the connection between AGA and lipid problems has not yet been fully established.

In Chakrabarty et al. study [5], AGA also had higher TG readings, higher blood pressure, and lower levels of HDL cholesterol.

In contrast to the control group, we observed that the CIMT has increased statistically significantly in the patient group.

A significant biomarker of subclinical atherosclerosis is proposed for carotid intima media thickness. It is assessed as a characteristic double line of the artery wall in B-mode in the carotid tree[6].

In the pathogenesis of atherosclerosis, the intimamedia complex of arterial walls may be a reflection of various stages during the development of disease: the hypertensive hypertrophic reaction of medial cells can be observed during the early atherosclerosis (CIMT quantified). In later stages of atherosclerosis, which is often seen in carotype plaque formation.

The common carotid artery (CCA) is usually observed as elevated CIMT, whereas carotid plaque building is more prevalent in carotid bifurcation (CB) or internal carotid artery (ICA). CB and ICA plaque development is linked to hyperlipidaemia and MI, whereas CCA increased CIMT is linked to hypertension and stroke [8].

However, the accuracy of CIMT is tangible in the absence of overt atherosclerosis as shown by people and animal models, which is the result of an age-related thickening of the intimate and medial layers of common carotid arteries. In the absence of atherosclerosis, pathological alterations in median hypertrophy or intimate thickening are not synonymous with atherosclerosis. Given that the shared underlying processes for start and development of illness, from pathologists' point of view, CIMT is a stronger predictor of the overall risk of coronary cardiac disease than an exact measuring of atherosclerosis [9], as documented in many studies.

Conversely, a link between a decrease in intimatemedia advance with lipid-reducing treatments and a decrease to cardiovascular risk demonstrated in clinical studies has led to proposing CIMT as a substitute endpoint for anti-therosclerotic medication. This is an essential feature in the risk assessment because CIMT occurs at an early stage of atherosclerosis, when treatment changes may make a significant difference in the course of the disease [10].

\section{Conclusion}

Increased CIMT in AGA patients indicates the responsibility of AGA patients for atherosclerosis.

\section{References}

[1] L.Yip, N.Rufaut, and R.Sinclair, "Role of genetics and sex steroid hormones in male androgenetic alopecia and female pattern hair loss: an update of what we now know," Australas. J. Dermatol., vol. 52, pp. 81-88, 2011.

[2] P.Hirsso, U.Rajala, M. Laakso, L. Hiltunen, P. Härkönen, and S. Keinänen-Kiukaanniemi, "Health-related quality of life and physical wellbeing among a 63-year-old cohort of women with androgenetic alopecia; a Finnish population-based study," Health Qual. Life Outcomes, vol. 3, pp. $1-7,2005$.

[3] V. A. Venning and R. P. R. Dawber, "Patterned androgenic alopecia in women," J. Am. Acad. Dermatol., vol. 18, pp. 1073-1077, 1988.

[4]M. W. Kim, I. S. Shin, H. S. Yoon, S. Cho, and H. S. Park, "Lipid profile in patients with androgenetic alopecia: a meta-analysis," J. Eur. Acad. Dermatology Venereol., vol. 31, pp. 942 951, 2017.

[5] S. Chakrabarty, R. Hariharan, D. G. Gowda, and H. Suresh, "Association of premature androgenetic alopecia and metabolic syndrome in a young Indian population," Int. J. Trichology, vol. 6, pp. 50, 2014.

[6] M.Bauer, S.Caviezel, A.Teynor, R. Erbel, A.A.Mahabadi, and A.Schmidt-Trucksäss, "Carotid intima-media thickness as a biomarker of subclinical atherosclerosis," Swiss Med. Wkly., vol. 142, pp. 43, 2012.

[7] R.A.Hegele, "The pathogenesis of atherosclerosis," Clin. Chim. acta, vol. 246, pp. 21-38, 1996.

[8] S.H.Johnsen and E. B. Mathiesen, "Carotid plaque compared with intima-media thickness as a predictor of coronary and cerebrovascular disease," Curr. Cardiol. Rep., vol. 11, pp. 21-27, 2009.

[9]A.VFinn, F.D.Kolodgie, and R.Virmani, "Correlation between carotid intimal/medial thickness and atherosclerosis: a point of view from pathology," Arterioscler. Thromb. Vasc. Biol., vol. 30, pp. 177-181, 2010.

[10]P.-J. Touboul et al., "Mannheim carotid intimamedia thickness consensus (2004-2006)," Cerebrovasc. Dis., vol. 23, pp. 75-80, 2007. 